Ocean \& Coastal Management

March 2015, Volume 106 Pages 124-135

http://dx.doi.org/10.1016/j.ocecoaman.2015.01.017

http://archimer.ifremer.fr/doc/00250/36153/

(c) 2015 Elsevier Ltd. All rights reserved.

\title{
Predicting fisher response to competition for space and resources in a mixed demersal fishery
}

\author{
Girardin Raphaël ${ }^{1,{ }^{*}}$, Vermard Youen ${ }^{2}$, Thébaud Olivier ${ }^{3,4}$, Tidd Alex ${ }^{5}$, Marchal Paul ${ }^{1}$
}

${ }^{1}$ IFREMER, Fishery Resource Lab, F-62321 Boulogne Sur Mer, France.

2 IFREMER, Unit Fisheries Ecol \& Modelling, Ctr Atlantique, F-44311 Nantes 03, France.

${ }^{3}$ IFREMER, UMR M101, AMURE, Unite Econ Maritime,Ctr Bretagne,ZI Pointe Diable, F-29280

Plouzane, France.

${ }^{4}$ Queensland Univ Technol, Sch Econ \& Finance, Brisbane, Qld 4001, Australia.

${ }^{5}$ Cefas, Lowestoft NR33 OHT, Suffolk, England.

* Corresponding author : Raphaël Girardin, email address : Raphael.Girardin@ifremer.fr ;

Youen.Vermard@ifremer.fr ; Olivier.Thebaud@ifremer.fr ; Alex.Tidd@cefas.co.uk ;

Paul.Marchal@ifremer.fr

\begin{abstract}
:
Understanding and modelling fleet dynamics and their response to spatial constraints is a prerequisite to anticipating the performance of marine ecosystem management plans. A major challenge for fisheries managers is to be able to anticipate how fishing effort is re-allocated following any permanent or seasonal closure of fishing grounds, given the competition for space with other active maritime sectors. In this study, a Random Utility Model (RUM) was applied to determine how fishing effort is allocated spatially and temporally by the French demersal mixed fleet fishing in the Eastern English Channel. The explanatory variables chosen were past effort i.e. experience or habit, previous catch to represent previous success, \% of area occupied by spatial regulation, and by other competing maritime sectors. Results showed that fishers tended to adhere to past annual fishing practices, except the fleet targeting molluscs which exhibited within year behaviour influenced by seasonality. Furthermore, results indicated French and English scallop fishers share the same fishing grounds, and maritime traffic may impact on fishing decision. Finally, the model was validated by comparing predicted re-allocation of effort against observed effort, for which there was a close correlation.
\end{abstract}

\section{Highlights}

- Effort allocation in a demersal fishery of the Eastern English Channel is modelled. Competition for space and resources between maritime activities is investigated. Fleets fishing with active gear are strongly influenced by scallop dredging métier. Larger vessels avoid maritime traffic, while small vessels operate in coastal areas. French fleets fish in the same areas as English one but avoid other French fleets.

Keywords: Effort allocation, Random Utility Model, Spatial competition, Demersal mixed fishery, Eastern English Channel, Spatial management 


\section{Abbreviations}

- DCF, Data Collection Framework;

- DPMA, Directorate for Marine Fisheries and Aquaculture;

- EAFM, Ecosystem Approach to Fisheries Management;

- IBM, Individual-Based Modelling;

- IFD, Ideal Free Distribution;

- IIA, Independence of Irrelevant Alternatives;

- LRI, likelihood ratio index;

- MSFD, Marine Strategy Framework Directive;

- RUMs, Random Utility Models;

- VSS, Vessel Separation System 


\section{Introduction}

According to the FAO (2012) most fisheries resources are already fully exploited or overexploited due in part to excess fishing capacity and fishing power. Fishing activities can also have adverse effects on the structure and functioning of marine ecosystems (Buchen, 2009; FAO, 2012). To address that challenge, many fisheries management agencies have adopted an Ecosystem Approach to Fisheries Management (EAFM) approach (Browman and Stergiou, 2004), by implementing management plans. This approach aims at maintaining or restoring fisheries resources to sustainable levels, while mitigating the adverse ecological impacts of fishing (Pauly et al., 2002). To accurately assess and evaluate fisheries management performances, it is essential to better understand the processes driving the dynamics of the marine ecosystems and the fishing fleets that impact them (Fulton et al., 2011; van Putten et al., 2011; Wilen et al., 2002).

Understanding and predicting the complex interactions between resource users and ecosystem dynamics is essential to reduce the risk of management failure (Hilborn, 2004). A founding principle of ecosystem-based management is that humans are fully part of ecosystems (Leslie and McLeod, 2007), and one of the main challenges for decision-makers is to better understand the factors that influence human behaviour (Wilson and McCay, 2001). This is of particular importance to fisheries managers who need to better understand the mechanisms of fishing effort allocation, so to better anticipate fishers' reactions to management.

Fishers' decision-making can be cast in terms of short- versus long-term choices (Van Putten et al., 2011). For example long-term choices include decisions about capital investment, or about whether to enter or exit a particular fishery (Nostbakken et al., 2011). Conversely shortterm decisions may consist of immediate actions, such as choosing a fishing area and/or a type of fishing activity (sometimes referred to as a métier") at the beginning of, or during a fishing trip, and also includes actions, such as discarding fish (Andersen et al., 2012; Hilborn, 1985; Hutton et al., 2004). In this study we concentrated on short-term behaviour, and in particular the factors that determined fishing effort allocation both spatially and across métiers. An increasing number of studies have investigated and modelled short-term fishers" behaviour using both conceptual and data driven approaches. Conceptual approaches include applications of the Ideal Free Distribution (IFD) theory (Gillis, 2003; Rijnsdorp et al., 2000), optimal foraging theory (Dorn, 2001), Individual-Based Modelling (IBM) (Millischer and Gascuel, 2006; Soulié and Thébaud, 2006) or vessel trajectory analysis (Bertrand et al., 2005; Vermard et al., 2010). Many data-driven approaches to fishers' behaviour modelling have built in Random Utility Models (RUMs). RUMs provide an appropriate and functional approach to describe how fishers make a choice among a panel of finite alternatives (Wilen et al., 2002). Such a discrete-choice modelling approach has been applied to analyse fishers' choice of fishing ground (Hutton et al., 2004; Wilen et al., 2002), target species (Pradhan and Leung, 2004a; Vermard et al., 2008), and gear type (Andersen et al., 2012; Holland and Sutinen, 1999; Marchal et al., 2009).

Fishers do not necessarily know all of the surrounding environmental factors and so may only have partial information about the precise position and availability of their target species. In most fleet dynamics studies, skippers have been assumed to choose their fishing ground, gear and/or target species, based on their own experience (e.g. their past choices/activity) and on their economic expectations for a given choice (e.g. past profit achieved). For example, fishers' behaviour can be influenced by fish price fluctuations, which are often seasonal and are an important factor to take into account when evaluating the expected profitability of alternative potential choices (Dupont, 1993; Loannides and Whitmarsh, 1987). Anecdotal evidence suggests that other factors which have seldom been considered in past 
empirical studies could determine fishers' behaviour. These factors include communication between fishers, or radar-screening of concurrent vessels which may indicate the presence of target species in a specific area. By contrast, skippers compete for space and resources, not only with other fishers, but importantly also with other sectors of activity operating in the same maritime areas. Exploitation of marine resources, for example aggregate extraction, offshore wind farms and maritime traffic can impact the choice of fishing grounds by restricting access or decreasing the availability of fish resources. In EU waters, the Marine Strategy Framework Directive (MFSD) of the European Union (EC, 2008a) requires that the different sectors of activity operating on the same maritime domain be managed jointly rather than in isolation. A key issue for fisheries managers then becomes to understand how fishers operate their activities and adjust their tactics in area-constrained environments.

To assess spatial constraint impact, this paper aimed to identify and quantify the determinants of fishing fleet dynamics in one of the most congested maritime area in the world, the Eastern English Channel (ICES Division VIId)(Figure 1). The analysis focused on French fleets catching flatfish species, sole (Solea solea) and plaice (Pleuronectes platessa). The flatfish species represent an important source of revenue for fishers in this area, however this fishery has important impacts on the marine ecosystem (Riou et al., 2001). Random utility modelling is used to gain insights into how fishers choose a métier and/or an area, at the scale of a trip, whilst interacting with other fishing fleets, maritime activities and spatial management (regulations). Maritime traffic in the Channel is thought to interact substantially with fishing activities due to it being one of the world busiest shipping lanes encompassing a large proportion of the Channel (Figure 1 and 2). The main form of spatial regulation for commercial fishing activities in the Channel is the coastal area within twelve nautical miles from the coastline (hereafter called the 12-mile zone") where trawling is prohibited to vessels with an engine power exceeding $221 \mathrm{~kW}$ or an overall length exceeding 24 meters. Finally we tested the predictive capability of the model to forecast effort reallocation one year ahead using two different predictors, and then predicted re-allocation of effort was compared against realised/observed re-allocation of effort.

\section{Materials and methods}

\subsection{Data}

\subsubsection{French fishing fleets}

French landings (in both weight and value) and fishing effort data are collected by the French Directorate for Marine Fisheries and Aquaculture (DPMA) from mandatory fishers' logbooks combined with sales slips information. They are available on the Harmonie" database of the Fisheries Information System managed by IFREMER. Landings in weight and value as well as fishing effort (in hours fished) are available by vessel, fishing trip, gear type and statistical rectangle (ICES rectangle with a surface of $1^{\circ}$ longitude $\times 0.5^{\circ}$ latitude, Figure 1 ). Price per species and per month was derived from the average monthly value of landings. Fishing vessels were categorised into Data Collection Framework (EC, 2008b, 2010; DCF) fleets based on the IFREMER national fleet register and trips were categorised into métiers based on monthly activity calendars (Marchal, 2008). Consistent with EC (2008a), a fleet represents hereby a group of fishing vessels sharing similar attributes in terms of technical characteristics (length class, horse power, capacity) and/or major activity (e.g., main gear used, main species targeted) during a particular year. Vessels belonging to a fleet group may still operate different fishing activities (hereby referred to as métiers) during the year. A métier is defined as a group of fishing trips targeting a similar (assemblage of) species, using similar gear, during the same period of the year and/or within the same area, and are 
characterised by a similar exploitation pattern. The different fleet and métier groups considered in this study are shown in Table 1.

We analysed fisheries data per vessel and fishing trip for the period 2007-2009. During a trip, vessels can operate in multiple ICES (International Council for the Exploration of the Sea) rectangles (Figure 1). Where a vessel visited several ICES rectangles in the same trip, the rectangle wherein it spent most of its fishing effort was attributed to the trip under consideration. The French vessels selected were those registered in the main Channel maritime districts (ICES Division VIId), i.e., Boulogne sur Mer, Cherbourg, Caen, Dieppe, Fécamp, Le Havre and Dunkerque (Figure 1). Those vessels, which had never fished in VIld during the period 2007-2009, were excluded from the analyses. Furthermore, analysis of the landing profiles of each fleet allowed us to determine the flatfish fishery by selecting flatfish landings which represented more than $2 \%$ of the total flatfish landings by weight in this area.

Allocation of the fleets' effort across métiers varied intra-annually. Figures 3 illustrates for all demersal trawlers smaller than $18 \mathrm{~m}$ (FL07, FL08 and FL09), polyvalent active gear fleets (FL38 and FL39), and for the dredger fleets (FL26 and FL27), the seasonal shift between dredging for molluscs (mainly performed in the winter) and bottom otter-trawling for demersal fish (mainly performed in the summer), or also midwater otter trawl for fleets polyvalent active gear fleets. In addition, an important part of the activity of the smallest trawlers and smallest dredgers (respectively <10 m, FL07, 10-12m, FL26) was composed of the -other métiers" (NOSZZ). In contrast, demersal trawlers larger than $18 \mathrm{~m}$ (FL10 and FL11) almost exclusively used bottom otter-trawl for demersal fish (NOSO5) throughout the year. Polyvalent passive gear fleets (FL43 and FL44) showed a more constant pattern of activity throughout the year, which was mainly dominated by trammel-netting (NOS34) for the larger vessels, and by the -other métier" group (NOSZZ) for the smallest vessels. A seasonal shift to dredging was observed for the 12-18 m fixed nets fleet (FL49), similar to that observed for the towed gear fleets (Figure3).

\subsubsection{Other sectors of activity and spatial restrictions}

The interactions between each of the French fleets presented in Section 2.2.1 were examined in relation to (i) other French and English fishing fleets, (ii) maritime traffic, and (iii) spatial management. The fishing activity of English vessels (mainly beam trawlers) was represented by their aggregate effort (in hours fished) per day and per ICES statistical rectangle. Most of the large-scale maritime traffic in the Channel occurs through a corridor referred to as the extended Vessel Separation System (VSS; Figure 2). For the purpose of this study, we assumed that the pressure exerted by maritime traffic on fishing activities to be represented by the percentage of an overlap of VSS on the ICES statistical rectangle. The 12-mile management zone was represented by the percentage of spatial overlap between this zone and each statistical rectangle. The spatial overlaps described above were calculated using a Geographic Information System (GIS) and then normalized with the surface of each statistical rectangle using R statistical software (R Core Team, 2012).

\subsection{Fleet dynamics modelling}

In order to understand and forecast fishing behaviour, we developed a discrete-choice model using a random utility function. Such models have been widely applied to analyse and model human behaviour and activities (Earnhart, 2002; Holland and Sutinen, 1999; McFadden, 1974; Sammer and Wüstenhagen, 2006). The main assumption of RUM is that individuals seek to maximize their utility (Pascoe and Robinson, 1998; Robinson and Pascoe, 1997; Wilen et al., 2002). Different explanatory variables were tested in order to identify the best model by running the RUM with different sets of explanatory variable (Table 2). A model was parameterized for each of the fleets shown in Table 1. 
Several RUM types building on different probability distributions have been used to model fishing choice behaviour. In the present case, two distributions have been considered. First, a conditional logit model (McFadden, 1974 ; Vermard et al., 2008) was used. This is the simplest sort of distributions to be considered, and also the one for which model outcomes are the easiest to interpret. A potentially critical aspect of this distribution model is that it should accommodate the property of independence of irrelevant alternatives (IIA). This IIA requires that for any choice alternatives, the relative odds of choosing one alternative rather than another are the same, irrespective of the availability of the other alternatives or consideration of their attributes (Train, 2003). A nested logit model was then also tested. Nested logit models impose a more complex hierarchical structure that could both alleviate the risk of failing the IIA property by limiting its application to alternatives of the same nest, and better mimic, at least conceptually, the fishers' decision-making process (Holland and Sutinen, 1999; Marchal et al., 2009).

For the conditional logit model, within a fleet, we assumed that at the start of a fishing trip, each individual vessel (v) may choose among several alternatives (i). Each alternative was defined by combining a métier and a statistical rectangle (Figure 1; Table 1). This allocation process is divided in two steps in the nested logit model, with at first, métier's choice corresponding to the nest and then within each nest, the area selection. All areas visited by fishing vessels outside Sub-Division VIld were merged in a unique area (named ZZZZ in this study). Each alternative was associated to a utility function.

\subsubsection{RUM explanatory variables}

The deterministic part of the Utility function $\left(U_{i}\right)$ was composed of 7 explanatory variables. We assumed that fishers choose their métier and fishing ground with the aim to maximize their returns based on their own experience and also on information gleaned from the other vessels in the same fleet operating the same métier, such as the profit realised by the fleet in the past (Holland and Sutinen, 1999; Marchal et al., 2009). We also assumed that fishers interact spatially with other French and English fleets and that they may be constrained by both Channel maritime traffic and the 12-mile zone.

The main economic variable driving effort allocation decisions was assumed to be $V P U E_{i}$ defined as the expected returns from choosing métier in a given area. To take into account the potential effects of price differences between species, $V P U E_{i}$ was derived by weighting past $C P \cup E_{i, s}$ aggregated per species group $\mathrm{s}$, month and métier, with current monthly average price $(€ / \mathrm{kg})$ per species Price $_{s}$ (Equation 1).

$$
\operatorname{VPUE}_{i}=\Sigma_{\mathrm{s}}\left(\mathrm{CPUE}_{i, s}{ }^{*} \text { Price }_{s}\right)
$$

Most studies of fishing decisions to date have shown that the decisions by fishers are also often based on their own past fishing patterns (i.e., there is a degree of adherence to traditional fishing grounds and/or métiers)(Holland and Sutinen, 1999, 2000; van Putten et al., 2011, 2013; Vermard et al., 2008). For this reason we included a variable $E F F_{i, v}$ which represents the past monthly average effort allocated for each alternative by each vessel. $E F F_{i, v}$ can be considered to represent the habits of fishers but also their knowledge of fishing grounds. Two different time lags (1 month and 12 month) were applied for each of the variables above (the suffixes_MONTH_1 and_MONTH_12 were added to distinguish between these two categories of lagged variables). The monthly average proportion of catch of a species s per unit of effort of a vessel $v, P O U R C \_C P U E_{i, v, s}$, was introduced in the model to represent the degree of targeting of specific species or groups of species by fishers. This was calculated for the top six species in terms of commercial value for the fleets under 
investigation. These included two flatfish species, sole (SOL) and plaice (PLE), seabass, Dicentrarchus labrax (BSS), cephalopods, Sepia officinalis and Loligo forbesi (CEPH) and cod, Gadus morhua (COD). Scallops (SCE), were also included as the main target species for the dredging fleets. Other species were aggregated in a seventh species group (OTHFF). Only one month lag was applied for those variables. This is because when the POURC_CPUE $E_{i, v, s}$ with 1- and 12-month lags were used in the same model, none of the other explanatory variables were significant, likely due to a problem of multiple correlations between explanatory variables which was not observed when only one of the two lagged variables was used. The two different time lags for the variables $V P U E_{i}$ and $E F F_{i, v}$ were kept, to explicitly represent the effect of seasonality in fishing some of the target species, and the influence on decisions of the most recent exploitation cues, hereby observed in the previous month.

To capture the impact of other fishing activities on fisher choices, three choice-specific variables were introduced in the model. The first, EFF_oth ${ }_{i}$, represents the spatial interaction with the other French fleets, and it is derived from the sum of monthly average current effort allocated by other fleets to a particular area. The second, $E F F \_G B_{i}$ is the mean cumulative effort allocated by English vessels to a particular area, and represents the spatial interaction between the French fleet under consideration and English vessels fishing at the same time.The two remaining explanatory variables that were calculated represent the spatial constraint exerted by maritime traffic and area-based management on the French fleets. SURF_AREA_OCCUP $i$ is the monthly average overlap between the extended VSS and the fishing grounds, and provides an estimate of the pressure exerted by maritime traffic per ICES rectangle. The variable SURF_12NM $i$ represents the 12-mile zone, and was calculated as the percentage of each statistical rectangle that overlapped with this restricted fishing zone. Finally, correlations have been tested between each couple of variables.

In summary, the deterministic part of the utility function was written as follows (equation 2):

$\mathrm{Ui} \sim V P U E_{i}+E F F_{i, v}+E F F_{-} o t h_{i}+E F F_{-} G B_{i}+\sum_{s} P O U R C \_C P U E_{i, v, s}+S U R F_{-} A R E A \_O C C U P_{i}$

+ SURF_12NMi $(2)$

\subsubsection{Model selection and probability}

The two different models, nested and conditional logit, were tested on each fleet. Both models were tested against the IIA hypothesis. The test consists of comparing the estimation of the model with the set of all alternatives $C$, with the same model using only a subset of alternatives $A$. Hausman and McFadden (1984) provide a description of this test which leads to the formulation of a test statistic $S$ (equation 3 ):

$$
S=\left(\theta_{A}-\theta_{C}\right)^{*}{ }^{*}\left[\operatorname{cov}\left(\theta_{A}\right)-\operatorname{cov}\left(\theta_{C}\right)\right]^{t *}\left(\theta_{A}-\theta_{C}\right)
$$

where $\theta_{A}$ and $\theta_{C}$ are respectively the maximum likelihood estimators of the conditional logit model with the subset of alternatives $A$ and the one with the set of alternatives $C$. This test statistic $S$ follows a $X^{2}$ distribution. The test is performed by comparing the full-alternative model with the model with one alternative missing, for each alternative. 
Selection of the best model is based on the McFadden's likelihood ratio index (LRI) (McFadden, 1974), which is similar to a $R^{2}$. The model was fitted to 2007-2008 data. The model retained can then be used to calculate the probability of each possible choice $\mathrm{i}$ by maximizing $U_{i}$. The calculus of this probability is detailed in equation 4 for the conditional logit model with $\mathrm{N}$ as the total number of alternative choices for a given fleet.

$P(i)=\exp \left(U_{i}\right) / \sum_{i=1: N} \exp \left(U_{i}\right)$

Concerning the two-level nested logit model, this probability may be described as (equation 5; Train, 2003):

$P(i)=P(m) * P(i \mid m)$

where $\mathrm{P}(\mathrm{i} \mid \mathrm{m})$ (equation 6 ) is the conditional probability that the skipper will choose the alternative i after having selected the métier $\mathrm{m} . \mathrm{P}(\mathrm{m})$ (equation 8 ) is the unconditional probability that the skipper will choose the métier $m$ before each trip. The deterministic component of $U_{i}$ can be derived on factors apply to the selection of a nest (a métier) hereafter called $Z$ and others use in the second decision step (ICES area) hereafter called $Y$. $\mathrm{P}(\mathrm{i} \mid \mathrm{m})$ can be expressed as

$P(i \mid m)=\exp \left(\beta^{\prime} Y_{i \mid m}\right) / \exp \left(I V_{m}\right)$

(6)

where $\beta$ is the parameter vector to be estimated, and

$I V_{m}=\log \left\{\Sigma_{i \in C m} \exp \left(\beta^{\prime} Y_{i \mid m}\right)\right\}$

is the inclusive value for métier $\mathrm{m}$. The unconditional probability of selecting à métier $\mathrm{m}$ is

$P(m)=\exp \left(\gamma^{\prime} Z_{m}+\sigma_{m} I V_{m}\right) / \Sigma_{m \in C} \exp \left(\gamma^{\prime} Z_{m} \sigma_{m} I V_{m}\right)$

(8)

where $\sigma_{m}$ is the inclusive parameter value for métier $m$ and $\mathrm{y}$ is the parameter to be estimated. The consistency of using a nested logit model is assessed by testing the null hypothesis $\sigma_{m}=1$ with a Wald $x^{2}$ test. 


\subsection{Forecast}

We used the models previously calibrated over 2007-2008 to forecast trip choices in 2009 . For each fleet, a set of explanatory variables was considered, and only the coefficients associated to the variables that best explained the model's variability $(p<0.05)$ were used to predict choices in 2009. The input data were derived from the same source of information that was used to describe the fleet choices over the 2007-2008 period, and these were processed in the same way. In many fisheries applications of discrete-choice models, the forecasted choice is taken to be that with the highest probability (see equations 4 and 5 ) (Marchal et al., 2009; Vermard et al., 2008). However, this approach appears to be rather ad $h o c$, and the prediction performances of the maximum probability estimator have to our best knowledge never been contrasted with those of alternative predictors, such as the median of the distribution.

In the present case, two methods of prediction were used. With the first method, the choice actually made is assumed to be as in previous studies, the alternative with the highest probability. The second method requires performing 200 simulations. Within each simulation, the choice is randomly selected from a multinomial distribution parameterized by the probability distribution derived from the model calibration. The frequency of each of the alternative choices actually made is then calculated for both methods for each month. For the second method, the median of the 200 frequencies obtained with the random iterations is defined as the frequency of forecasted choices.

To assess the capacity of each method to forecast the trip choice made in 2009 , the frequencies of forecasted choices per month are compared to the observed frequencies. $x^{2}$ tests are usually performed to compare observed and theoretical proportions. However, in our case, some choices will not be selected given the information provided by the explanatory variables. Because theoretical frequencies are used as denominators in the $x^{2}$ equation, null values will by construction compromise the utilization of that test. For that reason, another indicator has been calculated in order to evaluate the respective performances of the two prediction methods. This is the mean absolute error (MAE) weighted by the total number of trips per month obtained with each method, for each fleet (equation 9)(Willmott and Matsuura, 2005).

$M A E=\left[1 /\left(M^{*} N\right)\right]^{*} \sum_{\mathrm{i}=1: \mathrm{M}} \sum_{\mathrm{j}=1: \mathrm{N}} \mid F_{i, j}-$ Fpred $_{i, j} / / F_{i}$

Where $F_{i, j}$ is the frequency of observed choice $\mathrm{j}$ during month $\mathrm{i} ; F_{p r e d}$ is the frequency of the forecasted choices; $F_{i}$ is the total number of trips performed by a fleet during month $I ; N$ is the number of alternative choices for a given fleet; and $M$ is the number of months during which trips are operated. The method with the smallest MAE is considered to be the one which best predicted the global behaviour of the fleets. The package mlogit of the R 2.14 .1 software was used to estimate the model and perform the forecasts (Croissant, 2011; R Core Team, 2012).

\section{Results}

\subsection{Model goodness of fit}

The correlation between explanatory variable is most of time less than 0.2 , except for some fleets for which it can be around 0.5 (especially for variable VPUE or EFF with two different time lags), so all the variables previously described have been tested. The goodness of fit 
tests for the two models for each fleet using 2007-2008 data are presented in Table 3. For all fleets, the McFadden $\mathrm{R}^{2}$ was slightly higher when the nested logit model was used and the same result was observed with the likelihood ratio test. The IIA was tested for each fleet; however the property was never fully satisfied for the demersal trawlers of length below $10 \mathrm{~m}$ (Table 4). The statistic $S$ was often negative, which does not necessarily contradict with the IIA assumption (Hausman and McFadden 1984). Nevertheless, the S statistic is higher than the critical value for some alternatives (e.g., NOS22 29F1 for FL07, NOS34 outside area VIId and NOSZZ 27E9 for FL43 in Table 4), which contradicts the IIA property. Even if the model was further tested using the nested RUM (this approach relaxes IIA and assumes correlation across alternative choices e.g. (see, Ben-Akiva and Lerman, 1985), the IIA property within nests was still not fully satisfied. Moreover, the goodness of fit of both the nested and the conditional logit models, as given by the LRI index, were very similar, and there were overall little difference between model estimates (Figure 4). In addition, considering the result of the Wald $X^{2}$ test, nested models for $24-40 m$ demersal trawlers, $12-18 m$ vessel using polyvalent active gears and $12-18 \mathrm{~m}$ netters are considered similar to conditional logit models $(p>0.05$; Table 3). So, further analyses were performed using the most parsimonious model, the conditional logit model. Overall the model provided a good fit for all fleets in 2007-2008 and on average resulted in a McFadden LRI of $50 \%$ and a maximum value of $68 \%$ for the fleet of polyvalent passive gears of vessel $<10 \mathrm{~m}$. The other fleets resulted in a McFadden LRI of $30 \%$ which is still reasonable for a mixed fishery while the poorest fit observed was for the large demersal trawler' fleet, with a McFadden LRI of 17\% (Table 3).

\subsection{Parameter estimation}

\subsubsection{Expected economic opportunities}

The effort allocation of all demersal trawlers fleets (from FL07 to FL11) and all of the passive gear fleets $>10 \mathrm{~m}$ (FL44 and FL49) were always positively influenced by the variable VPUE_MONTH_12, while the effect of variable VPUE_MONTH_1 ${ }_{i}$ was dependent on vessel length and gave a negative coefficient for all demersal trawlers of length range $10-24 \mathrm{~m}$ (FL08, FL09 and FL10). By contrast, the effort allocation of all dredgers and polyvalent active gear fleets respectively (FL26, FL27, FL38 and FL39) was positively affected by the variable VPUE_MONTH_ ${ }_{1}$, while the impact of variable VPUE_MONTH_12 $i$ was dependent on vessel length (Table 5).

\subsubsection{Traditional fishing}

The current effort allocation of all fleets rigged with active gears (demersal trawlers, dredgers and polyvalent active gears) was negatively (or not) affected by their past short-term effort allocation, except for the fleet of demersal trawlers 24-40 m (FL11) and all of the passive gears, which were positively influenced by past effort in the same month in the previous year.

\subsubsection{Influence of other uses of maritime space}

Three different variables represent the potential spatial interactions, which may potentially interact with the French fishing fleet. These include (i) other fleets from France or England, (ii) maritime traffic, and (iii) the 12-mile zone where trawling is prohibited to large trawlers. The presence of English vessels reflected by the variable $E F F \_G B_{i}$ was positively correlated with several of the French fleets: $12-18 \mathrm{~m}$ demersal trawlers (FL09), $12-18 \mathrm{~m}$ dredgers (FL27), and all polyvalent vessels using active gears (FL38 and FL39). That presence has no effect on the other fleets. 
However, most of the French fleets tend to avoid areas with an overlap with other French fishing fleets, as represented by EFF_oth $h_{i}$ which always has a negative influence on the choice of a statistical rectangle.

The proxy representing maritime traffic, SURF_AREA_OCCUP , had a negative influence on the choice of activities by fleets of larger active gear vessels (FL09, FL10, FL27 and FL39), and also the 10-12 $\mathrm{m}$ passive gear fleet (FL44). However, the smallest demersal active gear fleets ( $<12 \mathrm{~m}$, FL07, FL08, FL26 and FL38) displays a positive or null coefficient. Choices by the fixed nets fleet (FL49) are also positively impacted by the maritime traffic overlap variable.

The proxy representing the overlap with the 12-mile coastal management area, SURF_12NM, has a positive coefficient for fleets consisting of small vessels: demersal trawlers under $10 \mathrm{~m}$ (FL07), 10-12 m polyvalent active gears fleet (FL38), under $10 \mathrm{~m}$ and 10-20 m passive gears fleet (FL43 and FL44).

\subsection{Forecasted fishing effort allocation (2009)}

The test of the two ways to forecast area and métier choice (based on either the maximum probability or the simulated median method) for 2009, indicated that the median value derived from a random sampling of 200 alternative within the multinomial probability distributions estimated by the RUM best matched the observations. As shown in Table 6, the MAE was always lower with the random sampling method than with the method using the maximum of probability as a choice. Only the small dredger fleet had a better forecast with the maximum of probability method. On average, the percentage of error in the prediction $(M A E)$ is low, in most cases less than $5 \%$, and always less than $10 \%$, which is confirmed by visual inspection (see examples in Figure 5).

\section{Discussion}

In this study different drivers of fishers' behaviour were quantified using a random utility modelling approach. A novel dimension of our investigation is that, in addition to the explanatory variables usually considered in this type of exercise (e.g., expected profit, tradition), we also considered the impact on the effort dynamics of selected French fleets, in terms of spatial interactions between fleets, the overlap with a spatially competing sector of activity (maritime traffic), and the area based management constraint (12-mile zone). Our results showed the existence of different behavioural dynamics, depending on the main gear used by the fleets and the size of the vessels in these fleets.

\subsection{Models' selection}

All of the models provided a reasonable fit to the 2007-2008 data, even though the IIA property was not satisfied. For spatial analysis, Wilen et al. (2002) have shown that the use of a conditional logit model often causes the IIA property to be at fault. An alternative used in many studies is the nested logit model (Holland and Sutinen, 1999; Marchal et al., 2009; Wilen et al., 2002). However, by considering nested model, the IIA property is still not satisfied within each nest and the information provided is similar to that obtained with the conditional logit model. Train (2003) suggested using the mixed logit model, for which the IIA property is relaxed. Although the mixed logit model can also include choices and individual characteristics, it is also more difficult to interpret, and so was not tested in this study. While 
the IIA property was not respected, the conditional logit RUM fitted the 2007-2008 fishing effort data well, providing satisfactory predictions compared to the actual 2009 data (average prediction error always lower than 10\%).

Another important finding of this study were the limitations associated with the maximum of probability method (e.g. amplification of model outliers) often used to simulate fisher's decision based on random utility models (e.g., Holland and Sutinen, 1999; Vermard et al., 2008; Marchal et al. 2009). We proposed here a method where an alternative is randomly sampled within the probability distribution derived from the RUM. This technique smoothens the predictions, and it also takes into account of the variability of the fitted model. However, this method is more computer-intensive due to the important number of simulations that are needed to reduce prediction error.

\subsection{Fishers' behaviour driven by past activities}

The decisions made by the different fleets in our models are strongly determined by the past activity of each fleet and more precisely by their activity in the previous year. However, the analysis of active demersal fleets also highlights the importance of scallop dredging in the Eastern Channel, which to a large extent determines the short term behaviour of these fleets. Scallop dredging is prohibited to French vessels between the $15^{\text {th }}$ of May and the $1^{\text {st }}$ of October, by ministerial order. Given the economic importance of this activity in the overall pattern of fishing of the fleets, any change in the regulation of this métier can be expected to induce important modifications in fisher behaviour. This regulation implies a seasonal switch in the métier choice of demersal active fleets (Figure 3), which is reflected in the estimated coefficients. Hence, fishers' métier choices are negatively impacted by their past short-term effort allocation, which confirms the strong seasonal variations in fishing effort observed for these fleets. The fleets maintain a similar pattern of choice from one year to another that is shown by the positive value of the variable associated to long-term habits.

The influence of expected returns differs between the demersal trawlers and the other active gear fleets. The positive impact of the VPUE_MONTH_1 on the small demersal trawlers, dredgers and polyvalent active gears (respectively FL07, FL26, FL27, FL38 and FL39) may be due to their ability to change métier relatively more easily compared to the larger demersal trawlers. Indeed, operators of these small trawlers are used to working across a greater diversity of fishing activities than those of larger trawlers. The large demersal trawlers (from FL08 to FL11) appear to be less reactive to changes in the relative profitability of alternative activities. Based on the model results, it appears that operators of these vessels tend to plan their fishing strategy based on the returns per métier in the previous year, when scheduling a change in the gear used and (or) in the area fished. The largest class of demersal trawlers (FL11) targeting fish (NOS05) as its main activity responds positively to variation in expected returns in the previous month, which could be explained by the fact that most of the activity of this fleet occurs outside of the Channel. The same hypothesis could be invoked to explain the behaviour of the passive gear fleet of vessels $10-12 \mathrm{~m}$ in length (FL44), the activity of which is mainly focused on the use of trammel net (more than half of the fleet's effort is allocated to this métier)(NOS34). The only fleet with a negative response to relative expected revenue in the previous year is the dredger fleets of $12-18 \mathrm{~m}$ vessels (FL27). This could be explained by two different hypotheses. Firstly, the effort allocation of this fleet could be explained by an increase of scallop biomass in 2008 compare to 2007. The impact of Scallop availability is shown in figure 3 where the proportion of effort allocated to the dredge métier (NOS01) in May 2008 (more than 60\%) is much higher than it was in May 2007 $(20 \%)$. Secondly, fishers could have reached their scallop catch quota earlier than expected in the 2007 season, which could also explain the previous observation. However, the results obtained with respect to this 12-month lagged variable must be interpreted with great caution, since only two years of data have been used in this study. 


\subsection{Is there an impact of spatial management and other maritime activities on fisher's behaviour?}

Large vessels fishing with active gears are spatially constrained by the fishing activity regulation within the 12-miles zone, inducing an allocation of their effort in the middle of the Channel. Their activity then competes with maritime traffic which is highly concentrated in this part of the Channel. Fishers seem to change their effort allocation during the period of the year with the most important shipping intensity, as shown by the negative coefficient for the variable SURF_AREA_OCCUP $i$ for demersal trawlers (FL09 and FL10), dredgers and polyvalent vessels using active gears (respectively FL27 and FL39). By contrast, the small demersal trawlers fleet (FL07) and the fixed nets fleet (FL49) choose fishing areas where traffic is intense. Fleets of small vessels using active gears (FL07 and FL39) focus their activity in the inshore area, as shown by the positive correlation with the variable SURF_12NM $M_{i}$ where (except in the Dover Strait) they are not impacted by shipping. This fleet spends most of its fishing activity near the Dover Strait where the maritime traffic is the most intense due to the narrowing of the strait in that part of the Channel but this fact is not captured by the model. Unlike larger boats, smaller vessels using active gears are also limited in terms of the distance to fishing grounds (these vessels operate daily trips, have limited fish storage capacity and limited engine power). For the fleet fishing with fixed nets (FL49), the Strait of Dover corresponds to the presence of their target species and more particularly sole, which could explain the positive correlation of their area choices with the

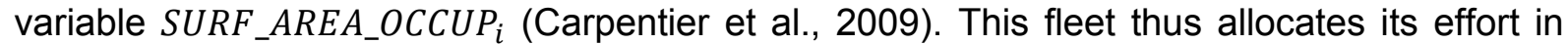
the statistical rectangle close to the Strait where shipping is the most intense. Moreover this fleet sets its nets on each side of the maritime traffic lines (Carpentier et al., 2009), while the demersal trawlers, dredgers and polyvalent vessels using active gears need to be able to travel across the VSS whilst fishing, which could explain the behaviour difference.

When the interaction between fishing fleets is significant, vessels seem to avoid areas occupied by other French fleets. Small vessels generally fish inshore, while larger vessels using active gears are not meant to be fishing within the 12 miles area, which could partially explain the spatial separation between these fleets. Another hypothesis could be that smaller vessels are able to profitably fish in areas with lower fish density than larger vessels. If this is the case, if localised depletion of fish or congestion of fishing capacity is observed in an area, smaller boats might be able to reallocate their effort to an area with lower fish density but with less competition. Moreover each target species get its own spatial repartition that could explain the difference of effort allocation observed between each French fleet. The model also, rather counter-intuitively, predicts that French 12-18 m demersal trawlers and dredgers, as well as both polyvalent active gear fleets (respectively FL09, FL27, FL38 and FL39) seem to prefer fishing in areas where UK vessels also allocate their effort. The English fleet is mainly composed of beam trawlers and dredgers both targeting the same species as the fleet segments in France. In particular, both the French and English vessels operate the métier targeting scallops (NOS01), a poorly mobile species, which probably explains why English and French fleets targeting scallops coexist on the same fishing grounds.

\subsection{Forecast 2009 data}

The forecasting model fitted the 2009 data reasonably well. This indicates that our model may be used to predict effort allocation one year ahead with a small level of error. By using the methods of forecast with several iterations, we take into account model variability and increase the accuracy of the prediction, even for the fleets with the weakest model fit. However RUMs are strongly data-driven and they need to be re-evaluated in case of a stepwise regime shift such as the introduction of a brand new spatial constraint (e.g., a 
marine protected area, or a wind farm). The model could be improved using finer scale data for fishing effort allocation (e.g. satellite based information). Such high resolution data could also be used to assess the impacts of aggregate extraction on fishing effort allocation. The use of detailed indicators of shipping intensity could also add information to our study.

\subsection{Perspectives}

To simulate the ecosystem conservation performances of different management regimes, this model needs to be integrated in a holistic modelling framework which can also predict the responses of the key target species to alternative harvesting patterns. Changes in spatial effort distribution and/or species targeting will change the dynamics of the underlying populations of these species, which might in turn lead to new changes in fishing effort allocation. Such a holistic model should in principle also take into account the process of entering and exiting the fishery. Some studies have already investigated this complex process (Le Floc'h et al., 2011; Pradhan and Leung, 2004b; Thébaud et al., 2006; Tidd et al., 2011), exploring the processes driving structural changes in fishing fleets. In the present paper the RUM can be used as the basis for a fleet dynamics sub-model in an existing holistic model such as ISIS-Fish (Pelletier and Mahévas, 2005), that simulates all the dynamics of the fishery from the biology of the target species to the response to management strategies, or Atlantis (Fulton et al., 2007) that takes into account all parts of the marine ecosystem in interaction with human activities and their management. Such coupled models can be used to test different management strategies and the effect of spatial interactions between different uses of the marine ecosystem.

\section{Conclusion}

In this study, RUMs have been used to understand fishers' behaviour interacting with other maritime activities in one of the busiest sea of the world, the Eastern English Channel. Several explanatory variables have been used in accordance with literature. To assess the impact of others maritime activities, the overlap between fishing activities, maritime traffic area and the 12 miles restricted management area has been built in our model. Finally, the between-fleets interactions are also represented in those models. Two different models have been tested, the conditional logit and the nested logit models. None of them fully satisfied the IIA property, and both fitted the 2007-2008 data similarly, so we selected the more parsimonious logit model in subsequent analyses. We showed that all of the fleets considered in this study were strongly influenced by their past activities with specific responses depending on the fleet considered. However, we also showed the importance of the maritime traffic which negatively impacted large vessels using active gears. To simulate the ecosystem conservation performances of different management, considering all of the interactions that occurred between the different maritime activities, this model needs to be integrated in a holistic modelling framework.

\section{Acknowledgements}

We gratefully acknowledge funding through the VECTORS project of the European Union (VECTORS of Change in Oceans and Seas Marine Life, Impact on Economic Sectors, contract no.266445), and from the IFREMER PhD grant system, as well as the support from the Wealth from Ocean Flagship and CSIRO Marine and Atmospheric Research. We are 
also indebted to the thorough comments on three anonymous reviewers, which greatly improved the manuscript.

\section{References}

Ben-Akiva, M., and Lerman, S.R. (1985). Discrete Choice Analysis: Theory and Application to Travel Demand. MIT Press Series in Transportation Studies. 390.

Andersen, B.S., Ulrich, C., Eigaard, O.R., and Christensen, A.-S. (2012). Short-term choice behaviour in a mixed fishery: investigating métier selection in the Danish gillnet fishery. ICES J. Mar. Sci. 69, 131-143.

Bertrand, S., Burgos, J.M., Gerlotto, F., and Atiquipa, J. (2005). Lévy trajectories of Peruvian purse-seiners as an indicator of the spatial distribution of anchovy (Engraulis ringens). ICES J. Mar. Sci. 62, 477-482.

Browman, H.I., and Stergiou, K.I. (2004). Perspectives on ecosystem-based approaches to the management of marine resources. Marine Ecology Progress Series 274, 269-303.

Buchen, L. (2009). Battling scientists reach consensus on health of global fish stocks. Nature News.

Carpentier, A., Coppin, F., Curet, L., Dauvin, J.-C., Delavenne, J., Dewarumez, J.-M., Dupuis, L., Foveau, A., Garcia, C., Gardel, L., et al. (2009). Channel Habitat Atlas for marine Ressource Management, final report / Atlas des Habitats des Ressources Marines de la Manche Orientale, rapport final (Charm phase II). INTERREG 3a Programme, IFREMER, Boulogne-sur-mer France. 626.

Christensen, V., and Pauly, D. (1992). ECOPATH II - a software for balancing steady-state ecosystem models and calculating network characteristics. Ecological Modelling 61, 169185.

Croissant, Y. (2011). mlogit: multinomial logit model. $R$ package version 0.2-2. http://CRAN.R-project.org/package=mlogit.

Dorn, M.W. (2001). Fishing behavior of factory trawlers: a hierarchical model of information processing and decision-making. ICES J. Mar. Sci. 58, 238-252.

Dupont, D.P. (1993). Price Uncertainty, Expectations Formation and Fishers' Location Choices. Marine Resource Economics 08.

Earnhart, D. (2002). Combining Revealed and Stated Data to Examine Housing Decisions Using Discrete Choice Analysis. Journal of Urban Economics 51, 143-169.

EC (2008a). Directive 2008/56/EC of the european parliament and of the council of 17 June 2008 establishing a framework for community action in the field of marine environmental policy (Marine Strategy Framework Directive). Official Journal of the European Union 22.

EC (2008b). Commission regulation (EC) No 665/2008 of 14 July 2008 laying down detailed rules for the application of Council Regulation (EC) No 199/2008 concerning the establishment of a Community framework for the collection, management and use of data in the fisheries sector and support for scientific advice regarding the Common Fisheries Policy. Official Journal of the European Union 3. 
EC (2010). Commission decision of 18 December 2009 adopting a multiannual Community programme for the collection, management and use of data in the fisheries sector for the period 2011-2013 (2010/93/EU). Official Journal of the European Union 64.

FAO (2010). The State of World Fisheries and Aquaculture 2010. Rome, FAO. 197.

FAO (2012). The State of World Fisheries and Aquaculture 2012. Rome, FAO. 209.

Le Floc'h, P., Daurès, F., Nourry, M., Thébaud, O., Travers, M., and Van Iseghem, S. (2011). The influence of fiscal regulations on investment in marine fisheries: A French case study. Fisheries Research 109, 257-264.

Fulton, E.A., Smith, A.D.M., and Smith, D.C. (2007). Alternative Management Strategies for Southeast Australian Commonwealth Fisheries: Stage 2: Quantitative Management Strategy Evaluation. Australian Fisheries Management Authority Report.

Fulton, E.A., Smith, A.D.M., Smith, D.C., and van Putten, I.E. (2011). Human behaviour: the key source of uncertainty in fisheries management. Fish and Fisheries 12, 2-17.

Gillis, D.M. (2003). Ideal free distributions in fleet dynamics: a behavioral perspective on vessel movement in fisheries analysis. Canadian Journal of Zoology 81, 177-187.

Hausman, J., and McFadden, D. (1984). Specification Tests for the Multinomial Logit Model. Econometrica 52, 1219-1240.

Hilborn, R. (1985). Fleet Dynamics and Individual Variation: Why Some People Catch More Fish than Others. Canadian Journal of Fisheries and Aquatic Sciences 42, 2-13.

Hilborn, R. (2004). Ecosystem-based fisheries management: the carrot or the stick? Marine Ecology Progress Series 274, 275-278.

Holland, D.S., and Sutinen, J.G. (1999). An empirical model of fleet dynamics in New England trawl fisheries. Canadian Journal of Fisheries and Aquatic Sciences 56, 253-264.

Holland, D.S., and Sutinen, J.G. (2000). Location Choice in New England Trawl Fisheries: Old Habits Die Hard. Land Economics 76, 133-149.

Hutton, T., Mardle, S., Pascoe, S., and Clark, R.A. (2004). Modelling fishing location choice within mixed fisheries: English North Sea beam trawlers in 2000 and 2001. ICES J. Mar. Sci. $61,1443-1452$.

Leslie, H.M., and McLeod, K.L. (2007). Confronting the challenges of implementing marine ecosystem-based management. Frontiers in Ecology and the Environment 5, 540-548.

Loannides, C., and Whitmarsh, D. (1987). Price formation in fisheries. Marine Policy 11, 143-145.

Marchal, P., Lallemand, P., and Stokes, K. (2009). The relative weight of traditions, economics, and catch plans in New Zealand fleet dynamics. Canadian Journal of Fisheries and Aquatic Sciences 66, 291-311.

McFadden, D. (1974). The measurement of urban travel demand. Journal of Public Economics 3, 303-328.

Millischer, L., and Gascuel, D. (2006). Information transfer, behavior of vessels and fishing efficiency: an individual-based simulation approach. Aquatic Living Resources 19, 1-13. 
Nostbakken, L., Thebaud, O., and Sorensen, L.-C. (2011). Investment Behaviour and Capacity Adjustment in Fisheries: A Survey of the Literature. Marine Resource Economics 26.

Pascoe, S.D., and Robinson, C. (1998). Input Controls, Input Substitution and Profit Maximisation in the English Channel Beam Trawl Fishery. Journal of Agricultural Economics 49, 16-33.

Pauly, D., Christensen, V., and Walters, C. (2000). Ecopath, Ecosim, and Ecospace as tools for evaluating ecosystem impact of fisheries. ICES Journal of Marine Science: Journal Du Conseil 57, $697-706$.

Pauly, D., Christensen, V., Guénette, S., Pitcher, T.J., Sumaila, U.R., Walters, C.J., Watson, R., and Zeller, D. (2002). Towards sustainability in world fisheries. Nature 418, 689-695.

Pelletier, D., and Mahévas, S. (2005). Spatially explicit fisheries simulation models for policy evaluation. Fish and Fisheries 6, 307-349.

Pradhan, N.C., and Leung, P. (2004a). Modeling trip choice behavior of the longline fishers in Hawaii. Fisheries Research 68, 209-224.

Pradhan, N.C., and Leung, P. (2004b). Modeling entry, stay, and exit decisions of the longline fishers in Hawaii. Marine Policy 28, 311-324.

Van Putten, I.E., Kulmala, S., Thébaud, O., Dowling, N., Hamon, K.G., Hutton, T., and Pascoe, S. (2011). Theories and behavioural drivers underlying fleet dynamics models. Fish and Fisheries 13, 216-235.

Van Putten, I.E., Gorton, R.J., Fulton, E.A., and Thebaud, O. (2013). The role of behavioural flexibility in a whole of ecosystem model. ICES J. Mar. Sci. 70, 150-163.

R Core Team (2012). R: A language and environment for statistical computing. R Foundation for Statistical Computing, Vienna,Austria. http://www.R-project.org.

Rijnsdorp, A.D., Broekman, P.L. van M., and Visser, E.G. (2000). Competitive interactions among beam trawlers exploiting local patches of flatfish in the North Sea. ICES J. Mar. Sci. 57, 894-902.

Riou, P., Le Pape, O., and Rogers, S.I. (2001). Relative contributions of different sole and plaice nurseries to the adult population in the Eastern Channel: application of a combined method using generalized linear models and a geographic information system. Aquatic Living Resources 14, 125-135.

Robinson, C., and Pascoe, S. (1997). Fisher behaviour: exploring the validity of the profit maximising assumption (Centre for the Economics and Management of Aquatic Resources).

Sammer, K., and Wüstenhagen, R. (2006). The influence of eco-labelling on consumer behaviour - results of a discrete choice analysis for washing machines. Business Strategy and the Environment 15, 185-199.

Soulié, J.-C., and Thébaud, O. (2006). Modeling fleet response in regulated fisheries: An agent-based approach. Mathematical and Computer Modelling 44, 553-564.

The World Bank (2005). Turning the tide - Saving fish and fishers: Building Sustainable and Equitable Fisheries and Governance. Washington, The World Bank 10. 
Thébaud, O., Daurès, F., Guyader, O., Travers, M., and Van Iseghem, S. (2006). Modelling the adjustement of fishing fleets to regulatory controls: the case of South-Brittany trawlers (France), 1990-2003. AMURE Publications. Working Papers Series D13-2006, 17.

Tidd, A.N., Hutton, T., Kell, L.T., and Padda, G. (2011). Exit and entry of fishing vessels: an evaluation of factors affecting investment decisions in the North Sea English beam trawl fleet. ICES J. Mar. Sci. 68, 961-971.

Train, K. (2003). Discrete Choice Methods With Simulation (Cambridge, UK: Cambridge University Press).

Vermard, Y., Marchal, P., Mahévas, S., and Thébaud, O. (2008). A dynamic model of the Bay of Biscay pelagic fleet simulating fishing trip choice: the response to the closure of the European anchovy (Engraulis encrasicolus) fishery in 2005. Canadian Journal of Fisheries and Aquatic Sciences 65, 2444-2453.

Vermard, Y., Rivot, E., Mahévas, S., Marchal, P., and Gascuel, D. (2010). Identifying fishing trip behaviour and estimating fishing effort from VMS data using Bayesian Hidden Markov Models. Ecological Modelling 221, 1757-1769.

Wilen, J.E., Smith, M.D., Lockwood, D., and Botsford, L.W. (2002). Avoiding Surprises: Incorporating Fisherman Behavior into Management Models. Bulletin of Marine Science 70, 553-575.

Willmott, C.J., and Matsuura, K. (2005). Advantages of the mean absolute error (MAE) over the root mean square error (RMSE) in assessing average model performance. Clim Res 30 , 79-82.

Wilson, D.C., and McCay, B.J. (2001). Fishery Management, Human Dimension. In Encyclopedia of Ocean Sciences, John H. Steele, ed. (Oxford: Academic Press), pp. 10231028. 
Table 1. Description of the fleets (a) and métiers (b) investigated in this study, as defined in the Data Collection Framework (DCF) of the European Union (EC, 2008). The fleets and métiers coding are specific to this study.

a)

\begin{tabular}{|c|c|c|c|}
\hline Gear type & Main gear & Vessels length (m) & Fleet code \\
\hline \multirow[t]{9}{*}{ Active gears } & Demersal Trawlers & $<10$ & FL07 \\
\hline & & 10-11.99 & FL08 \\
\hline & & $12-17.99$ & FL09 \\
\hline & & $18-23.99$ & FL10 \\
\hline & & 24-39.99 & FL11 \\
\hline & Dredgers & $10-11.99$ & FL26 \\
\hline & & 12-17.99 & FL27 \\
\hline & Vessels using Polyvalent 'active' gears only & $10-11.99$ & FL38 \\
\hline & & $12-17.99$ & FL39 \\
\hline \multirow[t]{3}{*}{ Passive gears } & ALL & $<10$ & FL43 \\
\hline & & 10-11.99 & FL44 \\
\hline & Fixed nets & $12-17.99$ & FL49 \\
\hline Other fleet & & ALL & FLZZ \\
\hline
\end{tabular}

b)

\begin{tabular}{lll} 
Gear & Fishing activity & Métier code \\
\hline Boat dredge & Molluscs & NOS01 \\
Bottom otter Trawl & Demersal fish & NOS05 \\
& Mixed cephalopods and demersal fish & NOS07 \\
Beam trawl & Demersal fish & NOS22 \\
Mid water otter Trawl & Small pelagic fish & NOS24 \\
Trammel net & Demersal fish & NOS34 \\
Others & & NOSZZ \\
\hline
\end{tabular}


Table 2. Description of the explanatory variables used in the Random Utility Model

RUM explanatory variables

\section{VPUE_MONTH_1}

VPUE_MONTH_12

\author{
EFF_MONTH_1 \\ EFF_MONTH_12 \\ EFF_OTH
}

EFF_GB

SPOURC_CPUE

SURF_AREA_OCCUP

SURF_12NM
Lag

Description

1 month

12 months

1 month

12 months

No lag

No lag

1 month

No lag

No lag
Profit expected by choosing a

given métier, based on value per

unit effort experienced in the past

with this métier

Habit of a vessel, reflected by past effort allocation by métier

Pressure exerted by other French

fleets in a given statistical

rectangle

Pressure exerted by English fleets

in a given statistical rectangle

Proportion of each main species in

the landing of a vessel one month

before the current trip

Spatial constraint exerted by

maritime traffic, estimated by the

proportion of each statistical

rectangle overlapped by the

extended vessel separation system

Spatial constraint exerted by the

12-mile coastal zone, estimated by the proportion of each statistical

rectangle overlapped by the

management area. 
Table 3. Comparison, for each fleet, of the model's goodness of fit to the 2007-2008 data, for the conditional logit model (MNL) and the nested logit model (NMNL) and test of the nested structure with a Wald $\mathrm{X}^{2}$ test. An alternative correspond to a métier and area choice combined.

\begin{tabular}{|c|c|c|c|c|c|c|c|}
\hline & & \multirow{2}{*}{$\begin{array}{l}\text { Number of } \\
\text { alternatives }\end{array}$} & \multicolumn{2}{|c|}{ McFadden $\mathbf{R}^{2}$} & \multicolumn{2}{|c|}{ LRTEST } & \multirow{2}{*}{$\begin{array}{c}\text { Wald } \chi^{2} \text { test } \\
\text { (p-wald) }\end{array}$} \\
\hline & & & MNL & NMNL & MNL & NMNL & \\
\hline \multirow[t]{5}{*}{ Demersal trawlers } & $<10 \mathrm{~m}$ & 16 & 0.68 & 0.69 & 4309.5 & 4358.8 & $90.18(<2.2 \mathrm{e}-16)$ \\
\hline & $10-12 m$ & 29 & 0.55 & 0.56 & 5796.2 & 5876 & $134.32(<2.2 \mathrm{e}-16)$ \\
\hline & $12-18 m$ & 38 & 0.41 & 0.42 & 3272.2 & 3364.9 & $81.71(<2.2 \mathrm{e}-16)$ \\
\hline & $18-24 m$ & 31 & 0.26 & 0.26 & 3208.5 & 3221.5 & 7.59 (0.022) \\
\hline & $24-40 m$ & 24 & 0.17 & 0.18 & 816.59 & 819.54 & $4.34(0.114)$ \\
\hline \multirow[t]{2}{*}{ Dredgers } & $10-12 m$ & 25 & 0.54 & 0.55 & 4874.4 & 4967.3 & $93.43(<2.2 \mathrm{e}-16)$ \\
\hline & $12-18 m$ & 56 & 0.38 & 0.39 & 12222 & 12272 & $60.69(6.64 \mathrm{e}-14)$ \\
\hline Polyvalent active & $10-12 m$ & 33 & 0.33 & 0.34 & 3435.1 & 3548.3 & $60.92(3.74 \mathrm{e}-13)$ \\
\hline gear & $12-18 m$ & 38 & 0.31 & 0.31 & 3789.4 & 3790.1 & $0.59(0.75)$ \\
\hline \multirow[t]{2}{*}{ All passive gear } & $<10 \mathrm{~m}$ & 21 & 0.68 & 0.68 & 28941 & 29298 & $197.11(<2.2 \mathrm{e}-16)$ \\
\hline & $10-12 m$ & 28 & 0.58 & 0.59 & 9838.5 & 9870.5 & $17.31(0.00017)$ \\
\hline Fixed nets & $12-18 m$ & 24 & 0.64 & 0.64 & 3252 & 3234.4 & $2.29(0.32)$ \\
\hline
\end{tabular}


Table 4. Tests for the IIA property, based on the S statistic, performed on demersal trawlers composed of vessels of less than $10 \mathrm{~m}$ and passive gear fleet composed of vessels of less than $10 \mathrm{~m}$.

FL07 FL43

\begin{tabular}{|c|c|c|c|c|c|}
\hline Deleted choice & S statistic & P-value & Deleted choice & S statistic & P-value \\
\hline NOS01 27E9 & Negative & & NOS34 27E8 & 34.22 & 0.27 \\
\hline NOSO1 out of VIId & 16.12 & 0.93 & NOS34 27E9 & 13.90 & 0.99 \\
\hline NOS05 27E9 & 15.01 & 0.96 & NOS34 27F0 & 1.27 & 1 \\
\hline NOS05 27F0 & 9.09 & 0.99 & NOS34 28E8 & Negative & - \\
\hline NOS05 28E9 & Negative & - & NOS34 28E9 & 17.80 & 0.96 \\
\hline NOS05 28F0 & Negative & - & NOS34 28F0 & Negative & - \\
\hline NOS05 28F1 & 6.53 & 0.99 & NOS34 28F1 & Negative & - \\
\hline NOS05 29F1 & 31.42 & 0.21 & NOS34 29F1 & 41.84 & 0.07 \\
\hline NOS05 out of VIId & Negative & - & NOS34 30F1 & Negative & - \\
\hline NOS22 28F1 & 1.16 & 1 & NOS34 out of VIId & 399.90 & $<0.0001$ \\
\hline NOS22 29F1 & 241.84 & $<0.0001$ & NOSZZ 27E8 & Negative & - \\
\hline NOS34 out of VIId & Negative & - & NOSZZ 27E9 & 338.32 & $<0.0001$ \\
\hline NOSZZ 27E9 & Negative & - & NOSZZ 27F0 & Negative & - \\
\hline NOSZZ 27F0 & Negative & - & NOSZZ 28E8 & Negative & - \\
\hline NOSZZ 28F0 & Negative & - & NOSZZ 28E9 & Negative & - \\
\hline NOSZZ 29F1 & Negative & - & NOSZZ 28F0 & Negative & - \\
\hline & & & NOSZZ 28F1 & Negative & - \\
\hline & & & NOSZZ 29F0 & Negative & - \\
\hline & & & NOSZZ 30F0 & 4.58 & 1 \\
\hline & & & NOZZZ 31F1 & 1.70 & 1 \\
\hline & & & NOSZZ out of VIId & Negative & - \\
\hline Degree of freedom & \multicolumn{2}{|c|}{26} & & \multicolumn{2}{|c|}{30} \\
\hline Critical chi-squared[df] & \multicolumn{2}{|c|}{38.89} & & \multicolumn{2}{|c|}{43.77} \\
\hline
\end{tabular}


Table 5. Parameters estimates from RUM on trip choice behaviour for each fleet. Only the significant parameters are shown and used to forecast the year

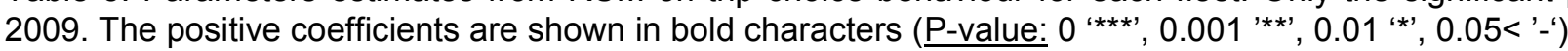

\begin{tabular}{|c|c|c|c|c|c|c|c|c|c|c|c|c|}
\hline \multirow[t]{2}{*}{ Variables } & \multicolumn{5}{|c|}{ Demersal Trawlers } & \multicolumn{2}{|c|}{ Dredgers } & \multicolumn{2}{|c|}{ Polyvalent active gears } & \multicolumn{2}{|c|}{ All Passive gears } & \multirow{2}{*}{$\begin{array}{l}\text { Fixed nets } \\
12-18 \mathrm{~m}\end{array}$} \\
\hline & $<10 m$ & $10-12 m$ & $12-18 m$ & $18-24 m$ & $24-40 m$ & $10-12 m$ & $12-18 m$ & $10-12 m$ & $12-18 m$ & $<10 m$ & $10-12 m$ & \\
\hline VPUE_MONTH_1 & $0.0050 * *$ & $-0.002^{*}$ & $-0.003 * * *$ & $-0.006 * * *$ & $0.0012 * * *$ & $0.0023 * * *$ & $0.0017^{* * *}$ & $0.0009^{*}$ & $0.0015^{* *}$ & - & $-0.0015^{* *}$ & - \\
\hline VPUE_MONTH_12 & $0.0104 * * *$ & $0.0056 * * *$ & $0.0042 * * *$ & $0.0012 * * *$ & $0.0016 * * *$ & - & $-0.0043 * * *$ & $0.0104 * * *$ & - & - & $0.0059 * * *$ & $0.0028^{*}$ \\
\hline EFF_OTH & $-0.064 * * *$ & - & - & - & - & - & $-0.0316 * * *$ & $-0.0434 * * *$ & $-0.0298 * *$ & $-0.0166 * * *$ & - & - \\
\hline EFF_GB & - & - & $0.0290 * * *$ & - & - & - & $0.0262 * * *$ & $0.0291 * * *$ & $0.0371 * * *$ & - & - & - \\
\hline EFF_MONTH_1 & $-0.096 * * *$ & - & $-0.015^{* * *}$ & - & $0.0106 * * *$ & $-0.0056^{*}$ & $-0.0051 * * *$ & $-0.0102 * * *$ & - & $0.0875 * * *$ & $0.0046 * * *$ & - \\
\hline EFF_MONTH_12 & $0.1364 * * *$ & $0.1052 * * *$ & $0.0678 * * *$ & $0.0147 * * *$ & $0.0214 * * *$ & $0.1018^{* * *}$ & $0.0681 * * *$ & $0.0105^{* * *}$ & $0.0741 * * *$ & $0.2370 * * *$ & $0.0290 * * *$ & $0.2591 * * *$ \\
\hline POURC_CPUE_SOL & $0.0414 * * *$ & $0.0300 * * *$ & $0.0268 * * *$ & - & - & $0.0607 * * *$ & $0.0430 * * *$ & $0.0462 * * *$ & $0.0320 * * *$ & $0.0509 * * *$ & $0.0321 * * *$ & $0.0340 * * *$ \\
\hline POURC_CPUE_PLE & $0.0959 * * *$ & $0.0651 * * *$ & $0.0318^{* * *}$ & - & - & $0.0144 *$ & $0.0526 * * *$ & $0.0313^{* * *}$ & $0.0427^{* * *}$ & $0.0309 * * *$ & $0.0707 * * *$ & - \\
\hline POURC_CPUE_BSS & - & - & $0.0943 * * *$ & - & - & - & $0.0180 * * *$ & - & $0.0263 * *$ & $0.0286 * * *$ & $0.0207 * * *$ & $0.2920 * * *$ \\
\hline POURC_CPUE_COD & - & $0.0677^{* * *}$ & $0.0248^{*}$ & $0.0400 * * *$ & - & $-0.1356 * *$ & $0.0909 * * *$ & $0.0237^{*}$ & $0.0664 * * *$ & $0.0102 * * *$ & $0.0216 * * *$ & $0.0382 * * *$ \\
\hline POURC_CPUE_SCE & $0.0257 * * *$ & $0.0255^{* * *}$ & $0.0235^{* * *}$ & $0.0859 * * *$ & - & $0.0411 * * *$ & $0.0242 * * *$ & $0.0237 * * *$ & $0.0183 * * *$ & - & $0.0569 * * *$ & $0.0165 * * *$ \\
\hline POURC_CPUE_CEPH & $-0.0426^{*}$ & $0.0158 *$ & $0.0400 * * *$ & $0.0262 * * *$ & $0.0140 * *$ & $0.0803 * * *$ & $0.0098 * * *$ & - & - & $0.0359 * * *$ & $0.0241 * * *$ & - \\
\hline POURC_CPUE_OTH & $0.0540 * * *$ & $0.0354 * * *$ & $0.0341 * * *$ & $0.0228 * * *$ & $0.0095^{* * *}$ & $0.0386 * * *$ & $0.0400 * * *$ & $0.0320 * * *$ & $0.0325 * * *$ & $0.0340 * * *$ & $0.0427 * * *$ & $0.0302 * * *$ \\
\hline SURF_AREA_OCCUP & $0.1506 * *$ & - & $-0.008^{* * *}$ & $-0.006 * * *$ & - & - & $-0.0071 * * *$ & - & $-0.0060 * *$ & - & $-0.0037^{*}$ & $0.0060^{*}$ \\
\hline SURF_12NM & $0.0019 *$ & - & - & - & - & - & - & $0.023 * * *$ & - & $0.0028 * * *$ & $0.0043 * * *$ & - \\
\hline
\end{tabular}


Table 6. Comparison of two methods to forecast the trip choice in 2009 based on the parameter estimates from discrete choices models previously analysed. The MAE (Mean absolute error) of each method is shown for each fleet.

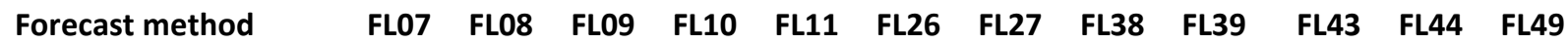

\begin{tabular}{lllllllllllll}
\hline $\begin{array}{l}\text { Maximum of } \\
\text { probability }\end{array}$ & 8.32 & 2.06 & 1.89 & 1.62 & 3.02 & 2.65 & 1.24 & 3.49 & 2.48 & 5.5 & 1.40 & 2.31 \\
$\begin{array}{l}200 \text { random } \\
\text { iterations }\end{array}$ & 6.64 & 2.01 & 1.83 & 1.60 & 2.50 & 2.71 & 1.12 & 2.65 & 2.324 & 3.51 & 1.07 & 2.14 \\
\hline
\end{tabular}




\section{Figures}

Figure 1 Statistical rectangles and main fishing harbours in the Eastern English Channel (ICES Sub-Divisions VIId)

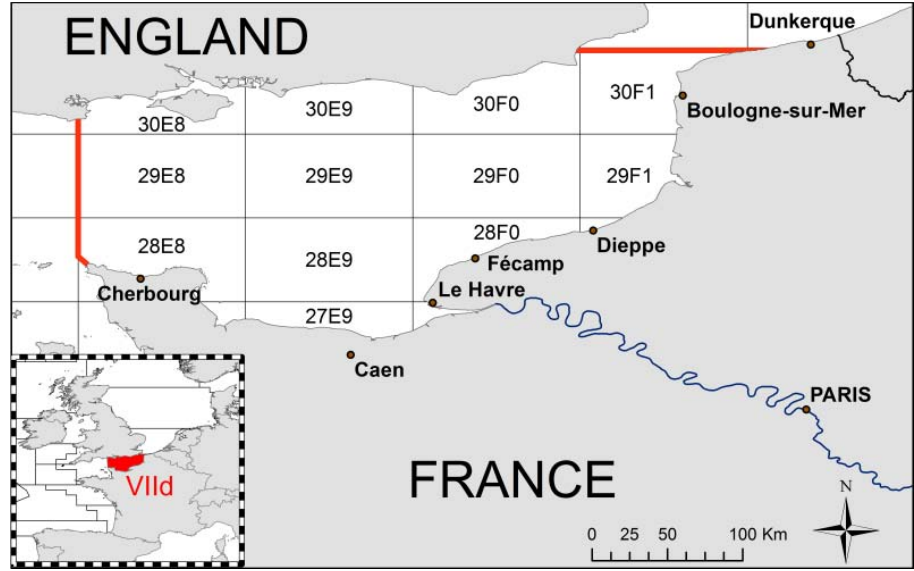

Figure 2 Intensity of the other use of the maritime area in the Eastern English Channel per ICES pixel $\left(0.05^{\circ}\right.$. of longitude $\times 0.05^{\circ}$. of latitude) in 2008 . The maritime traffic is represented in green. The aggregate extraction is in blue and the daily average cumulated effort of the English fishery is represented in shade of red (data derived from VMS data in 2008).

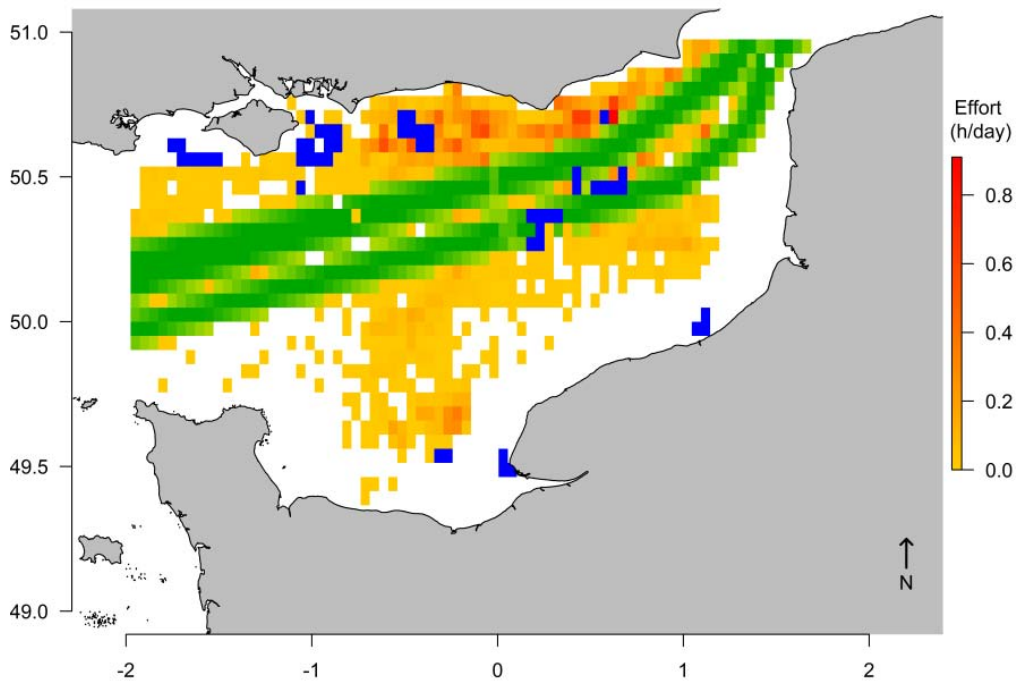


Figure 3 Proportion of métiers used by each selected fleet per month in 2007 and 2008, in percentage of trip chosen (Data used derived from French logbooks and monthly activity calendars).

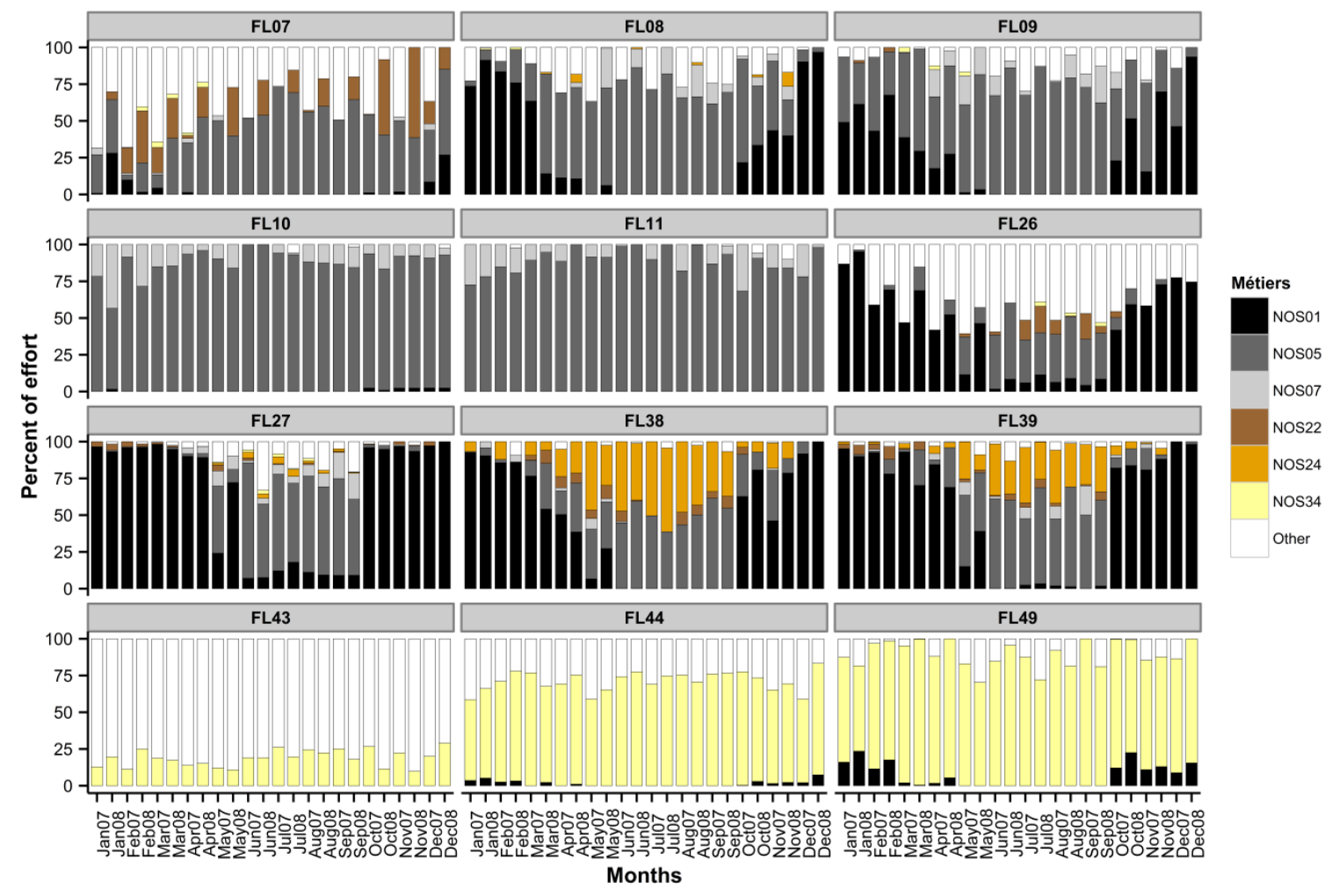


Figure 4 Comparison of each estimate per selected fleet. Grey bars represent the conditional logit model and orange one the nested logit model with the choice of a métier for the first level and an ICES area for the second level. Only significant estimates are presented.

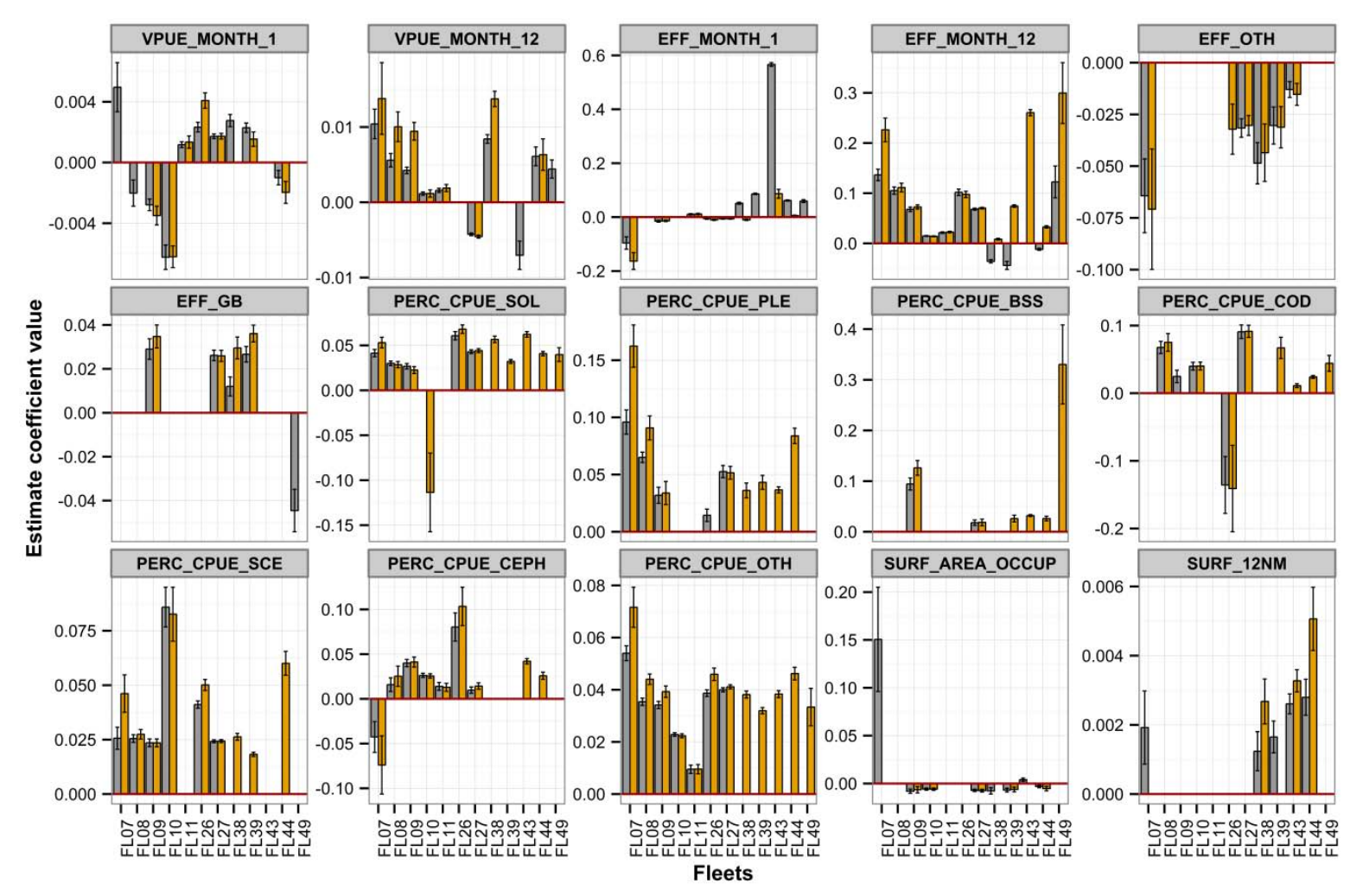


Figure 5 Example of forecast of data in 2009 in number of trips per month for most frequent alternative choice of each fleet: the fleet FL07 when other métiers are chosen in the area 27F0; the fleet FL08 when bottom otter trawling for demersal fish in area 27E9; the fleets FL09, FL10, FL11 when bottom otter trawling for demersal fish in the outside of area VIld; the fleet FL26 when other métiers are chosen in the area 29F1; the fleet FL27 when dredging for molluscs in the area 29F0; the fleets FL38 and FL39 when dredging for molluscs in the area 27E9; the fleet FL43 when other métiers are chosen outside of area VIld; the fleets FL44 and FL49 when trammel netting for demersal fish in the area 30F1. The dark line represents the observed choice in 2009 , the red line represents the forecast based on the maximum of probability predictor, the green dotted line represents the median predictor derived from the 200 random iterations and the green area represents the range of predictors obtained with the 200 random iterations.
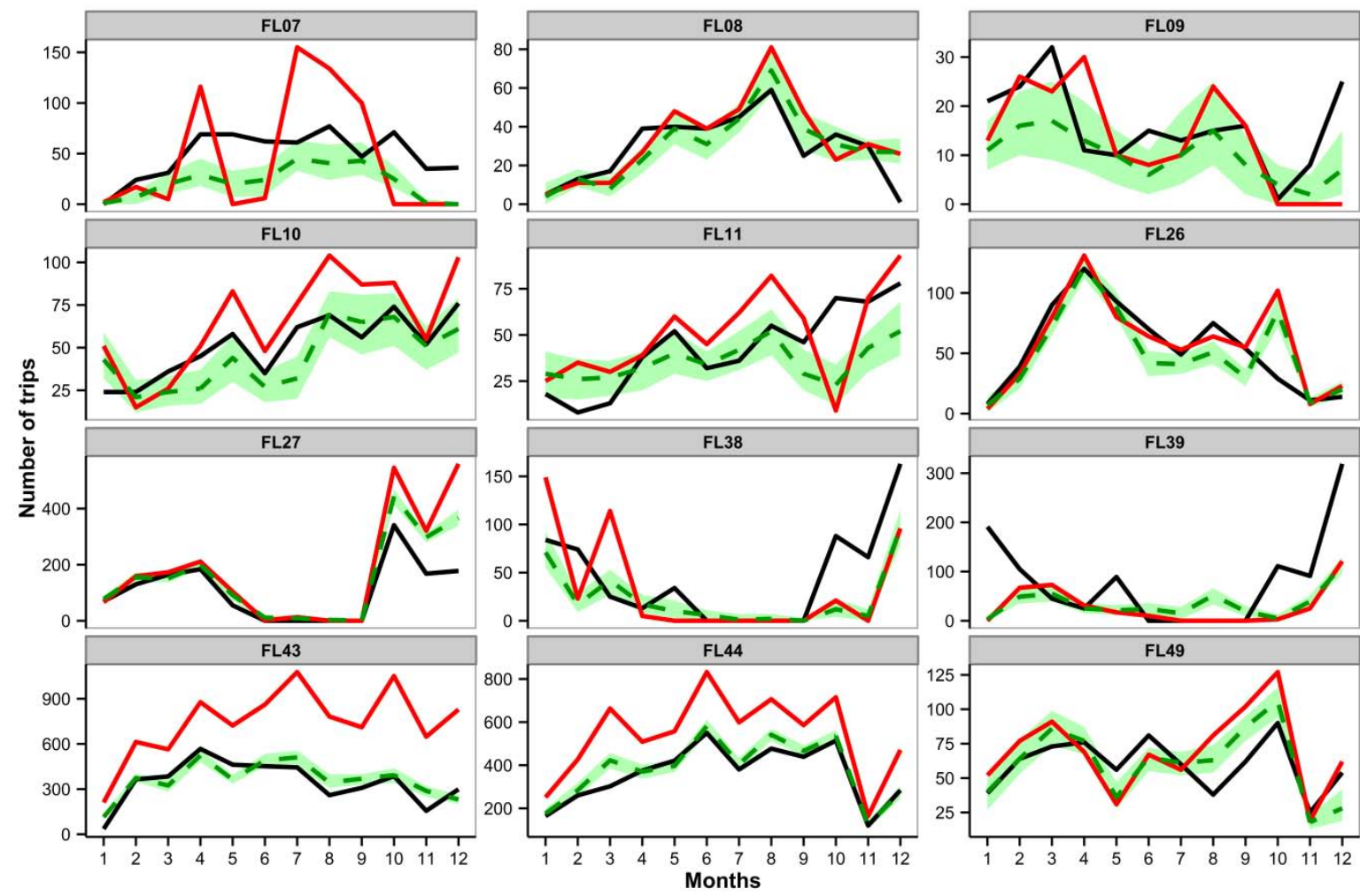